\title{
Influence of land use change on hydrology of shallow water table environments
}

\author{
M. S. De Silva ${ }^{1} \&$ M. H. Nachabe ${ }^{2}$ \\ ${ }^{1}$ School of Engineering Technologies, Lethbridge College, Canada \\ ${ }^{2}$ Department of Civil and Environmental Engineering, \\ University of South Florida, USA
}

\begin{abstract}
Land development through urbanization plays a significant role in changing the hydrology of a watershed. A two-dimensional finite element variable saturation flow model is coupled with a digital terrain analysis to quantify the impacts of urbanization on the hydrology of shallow water table environments. The ground surface is sealed to infiltration for a fraction of the surface corresponding to urbanized land. A $75 \%$ increase in urbanization reduces the cumulative transpiration by $86.4 \%$, cumulative infiltration by $76.4 \%$ and base flow by $55.5 \%$. Simulations to assess the influences of slope on local hydrology indicated that landscapes with mild slopes have less base flow than landscapes with steep slopes. Effect of surface slope on infiltration is found to be negligible due to the presence of high porosity sandy soil at this site.
\end{abstract}

Keywords: urbanization, transpiration, infiltration, base flow.

\section{Introduction}

Rapid increase in twentieth century population triggered unprecedented growth in urban land development. Urbanization refers to the transformation of rural culture, economy, and life style into an urban setting, where people are living in towns and cities. The United Nations [1] defines settlements of over 20,000 as urban, and those with more than 100,000 as cities. A metropolitan area includes both urban areas and rural areas that are socially and economically integrated with a particular city. According to 2005 revision of the UN World Urbanization Report, the global proportion of urban population rose dramatically from $13 \%$ (220 million) in 1900 , to $29 \%$ (732 million) in 1950 , to $49 \%$ (3.2 billion) in 
2005. The same report predicted that the figure is likely to rise to $60 \%$ ( 4.9 billion) by 2030 and it is estimated that in 2050 over 6 billion people, over two thirds of the world population are living in cities and towns [2]. Therefore the problems associated with increase in land development would be much severe.

In general urban land use changes topographic attributes especially surface cover conditions and ground slope. Change in land use pattern associated with urbanization includes roads, buildings, and other paved surfaces are often associated with a proportional reduction in vegetated surfaces [3]. In addition, urbanisation alters ground slope due to numerous construction and development activities. According to an EPA publication [4], $75 \%-100 \%$ increase in impervious cover may increase the surface run-off from $10 \%$ to $55 \%$, decrease evapotranspiration from $40 \%$ to $30 \%$ and decrease deep infiltration from $25 \%$ to $5 \%$. The natural drainage system protects the catchment by temporarily storing and then gradually releasing surface and subsurface flows. The slow release of surface and subsurface flows, often known as base flow, support the low flow and the aquatic life in streams and other water bodies. However, due to land development natural drainage systems are impacted. When storm water run-off travels across impervious cover, it channels rapidly a significant amount of urban runoff and pollutants [5].

When the total impervious area of a watershed is over 25 percent, serious degradation of downstream ecosystems occur due to disruption of natural flow regimes, increase in water temperatures, and reduction in base flows. A report linking science and policy for urban non-point source pollution in the Great Lakes region, concluded that urban non-point source pollution and related imperviousness surfaces constitute one of the most complex scientifically and politically environmental challenges facing the Great Lakes community (IAGLR [6]). A study of the Puget Sound regional ecosystem, a once forested region, concluded that if tree canopy lost since 1973 were replaced, the region would have saved $\$ 2.4$ billion in storm water containment services during that 25 year period (American Forest [7]).

Due to the rapid increase in computational modeling capabilities, it is now possible to visualize and simulate the change in eco-hydrology associated with urbanization and alteration in topographic attributes. The main purpose of this research is to develop a tool which will guide local stakeholders and administrators on their decisions in future land development activities considering the long term impacts of the change in land use. In this study we couple a two-dimensional finite element variable saturation flow model, HYDRUS-2D (Simunek et al. [8]) with digital terrain analysis to quantify and demonstrate the sensitivity of the change in surface runoff, infiltration, base-flow and transpiration due to an increase in impervious cover and change in ground slope for a 'slice of land' or hillslope. The hillslope connects atmospheric fluxes to the land surface for the landscapes at Lithia, west central Florida, which has a shallow water table environment. Precipitation and Potential Evapotranspiration (PET) values are used as the time variable driving boundary condition at the ground surface. 


\section{Study area}

The study area is in Lithia around the Tampa Bay Regional Reservoir in the southeastern portion of Hillsborough County, west central Florida. As shown in fig. 1, a flow path is delineated from topo maps, and series of wells from PS1 to PS5 are used to monitor the surficial water table aquifer. The flow path is $295.35 \mathrm{~m}$ long with an average slope of $1.4 \%$. The vegetation cover from PS1 to PS4 is grass and from PS4 to PS5 is forested wetland that consists of pine, oak, and maple trees. Predominant soil type in the area is Myakka fine sand with pockets of Mulat fine sand, which were characterized as deep, poorly drained, and very poorly drained sands. The sand at this site is fairly typical of soils in west central Florida, south of Tampa Bay. Permeability is high in the surface and subsurface layers (Carlisle et al. [9]). The topography of the site varies from $+23.04 \mathrm{~m}$ to $+27.00 \mathrm{~m}$ above National Geodetic Vertical Datum (NVGD). According to the recent water level measurements done at the site, surficial aquifer is relatively shallow (about $4.6 \mathrm{~m}$ ) and poorly connected to the intermediate aquifer below. The study area has a humid subtropical climate having a cool dry season and a warm rainy season, constituting a strong climate cycle. According to the precipitation data collected by the University of South Florida in 2001-2002, the mean yearly rainfall is $1.57 \mathrm{~m}$. The mean yearly PET at Bowling Green, $26 \mathrm{~km}$ south east of the study area, obtained from South West Florida Water Management District (SWFWMD) is $1.08 \mathrm{~m}$. The site is a nondeveloped area with some native vegetation and has been utilized in the past for cattle ranching and farming.

\section{Field data}

An intensive fieldwork was carried-out to collect the independent data necessary for the simulations. The field instrumentation consisted of high accuracy $+/-$ $2 \mathrm{~mm}$ resolution pressure transducers (Instrumentation Northwest, Inc (INW) PS9800) and data loggers set to 5 minutes temporal resolution to measure water level fluctuations in observation wells and continuous 20 minutes tipping bucket rainfall gauging to collect rainfall intensity. Pressure transducers were calibrated before installation, and after that their readings were frequently compared with manual observations of water levels at the site. Soil samples were collected using hollow stem auger and split-spoon sampling methodology at two locations (PS1 and PS5). Altogether 8 samples were collected and samples were analyzed in the lab to determine the saturated hydraulic conductivity (using falling head permeability test), aquifer thickness and porosity. The ET data obtained from SWFWMD weather station at Bowling-Green uses the Penman-Monteith method to compute PET rates. Topography of the area was surveyed using total station surveying equipment (TOPCON, Tokyo Optical Instruments). 


\section{Hydrological model}

Two dimensional finite element variable saturation flow model is used to simulate the water flow driven by precipitation and ET, in a transect in the $\mathrm{x}-\mathrm{Z}$ plane (Simunek et al. [8]). Galerkin type linear finite element method for space is applied for discretization, and a finite difference method for temporal discretization to solve the two-dimensional variably saturated flow (Richards) equation.

$$
\frac{\partial \theta(x, z, t)}{\partial t}=\frac{\partial}{\partial z}\left[K(\theta)\left(\frac{\partial h(\theta)}{\partial z}-1\right)\right]+\frac{\partial}{\partial x}\left[K(\theta)\left(\frac{\partial h(\theta)}{\partial x}\right)\right]-S
$$

where, $\theta(x, z, t)$ is the water content of the soil, $h(\theta)$ is the matric potential head, $z$ is the depth dimension, $x$ is the horizontal dimension, $K(\theta)$ is the unsaturated hydraulic conductivity function, $t$ is time, and $S$ is a sink term representing the root water uptake. The macroscopic alpha model developed by Feddes et al. [10] which assume root water uptake as a function of water stress conditions in the soil is used to estimate the term ' $S$ '.

Although introduced recently, the model is widely accepted in both the research and engineering communities. The model has been extensively verified by Simunek et al. [8] by comparing model results with available analytical solutions for solute transport and with other numerical model results for water flow. Furthermore, an independent team of hydrologists tested the performance and capabilities of the model and found that the model was reliable. The results of their findings are published in the Software Spotlight section of Ground Water (Diodato [11]).

\section{Model set up}

By scrutinizing the soil investigation data, it was revealed that the soil texture and soil properties are fairly uniform down to an elevation of $21.3 \mathrm{~m}$ and can thus be represented by one set of soil hydraulic parameters. Additionally, since the underlying layer consists mainly of clay, this layer can be assumed to represent a no-flow boundary. To visualize the complexity of the landscape and topography at the Long Flat Creek, a DEM, which represents the terrain surface as a lattice of point elevation is developed from one-foot contour and used to extract the topographic settings of the landscape in the source area. In a DEM, the shape of the surface is represented by the change in elevation between adjacent lattice points. Most of the primary topographic attributes such as slope, curvature, altitude, upslope area etc. can be estimated locally from the derivations of the topographic surface. These derivatives measure the rate at which elevation changes with respect to changes in location. The topographic elevation from the identified pathway becomes the upper geometry for simulations.

Soil hydraulic properties characterizing soil water retention and permeability were assumed to be described by an analytical model of van Genuchten [12]. 


\subsection{Simulating the influences of urbanization}

Initial condition is specified so that it reflects the position of the water level in the creek and in the observation wells. The hydrostatic equilibrium is assumed both below and above the groundwater level. Computed daily PET and measured daily precipitation rates are used as the time variable boundary conditions at the soil surface. Since no open water bodies, except the creek at the lower end of transect exist, the atmospheric potential transpiration is distributed over the root zone as the potential root water uptake. The observed water level elevations at PS5 are utilized to specify the variable pressure head boundary condition at the lower end of the domain. Water divide (no flow) boundary condition is assumed for the upper end of the domain.

\subsection{Simulating the influences of topography}

The surface topography shown in the DEM is relatively flat with an average slope of $1.4 \%$. This slope represents an average for central and southern Florida landscapes. During land development ground slope is changed creating new landscapes. To assess the influences of slope on local hydrology two slopes one milder $(0.5 \%)$ and the other steeper (2.5\%) than the existing slope, are utilized to illustrate the influences of slope. To isolate the effect of slope, the initial water level elevation $0.38 \mathrm{~m}$ below and parallel to the ground surface is assumed. Hydrostatic pressure equilibrium is assumed both below and above the ground water level. The boundary condition at the upper end is assumed as a water divide (no flow boundary condition). Constant pressure head reflecting the water level elevation at the creek is used for the lower end boundary. The same atmospheric boundary condition which used to simulate the impacts of urbanization is also used to simulate the influences of topography.

\section{Result and discussion}

The selection of a finite element model element model for this study was justified by two main reasons. First, finite element mesh accommodates the irregular shape of the ground surface. The use of a triangular finite element meshes to describe the transport domain geometry is more flexible. Second, the model accommodates system-dependent boundary conditions, which cannot be specified a priori. System dependent conditions are adjusted based on state variable and system response. The root water uptake flux to the atmosphere is considered to be a system dependent condition, since it depends on soil moisture conditions. The seepage face is also considered a system-dependent boundary condition that depends on actual moisture conditions on the particular boundary (Simunek et al. [8]). Numerical convergence of the model depends to the large degree on size of finite elements, especially in areas with large fluxes and steep hydraulic gradients. As the size of the finite elements decreases the solution will tend to the exact solution. Therefore, a fine finite element mesh was used closer to the land surface. Also, the resolution of the finite element mesh closer to the 
creek was made finer to approximate the steep hydraulic gradients in this portion of the domain. The finite element mesh provided stable numerical simulations and further refinement of the mesh did not alter the numerical results. Because the numerical stability of the finite element model depends strongly on the used time steps, values of $0.01,0.01$ and 0.1 days were adopted as initial, minimum, and maximum time steps.

The surface is sealed for infiltration for a fraction of the surface corresponding to urbanized land. A five months period (150 days) having both dry and wet periods starting from October'01 is used to create the atmospheric boundary condition applied at ground surface. Atmospheric boundary conditions are rainfall during a storm and PET afterwards. Since riparian zone is the most diverse and valuable habitat area, during the land development stage riparian corridors are normally left enacted. Therefore, when demarcating the urbanized areas, we assume only the upland is developed. We seal the ground surface $50 \%$, and $75 \%$ to represent the percentage of urbanization. The finite element-mesh, and time steps used for calibration (De Silva [13]), are also used to simulate the influences of urbanization. In all simulations the atmospheric boundary conditions are maintained the same to isolate the impact of increase in impervious surface.

Measured water levels and precipitation at the site are shown in fig. 1. Although gaps in the dataset exist, graphical presentation of the data shows similar trends with some isolated outliers for the monitored period. During the dry period (from October to March) water levels are lower. During a storm water levels rises and then gradually decreases. As shown in fig. 2, the computed PET rates shows, both the diurnal and seasonal fluctuation of PET. Diurnal fluctuations represent daily variation of solar radiation and seasonal fluctuations are attributed to the changing weather condition from summer to winter and winter to summer.

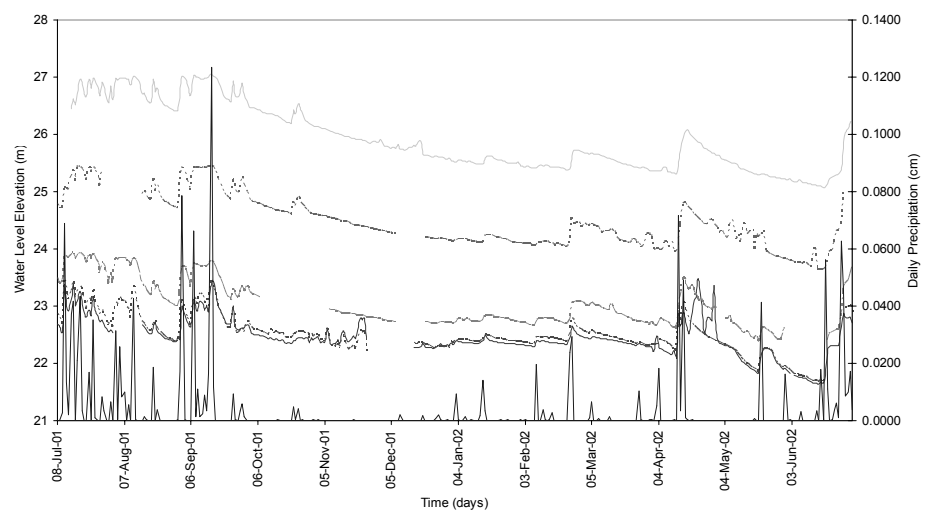

Figure 1: Observed daily water levels and precipitation. 


\subsection{Impacts of increase in impervious cover on transpiration}

The increase in urbanization causes a decrease in transpiration due to the removal of trees and lowering of the water table. Potential transpiration represents an atmospheric demand, whereas actual transpiration represents the ability of a plant to release water. Thus actual transpiration depends on the vegetated rooting density, soil conditions and the availability of soil moisture. The sink term in Richard's equation, eqn. (1) distributes potential evapotranspiration atmospheric demand over the root zone and controls the water loss from the crop according to the soil water status. From October to the middle of March the PET is low and during the summer from the middle of March to July PET is high. The seasonal variation in PET can be attributed to change in solar radiation variability, fig. 2 and moisture availability, fig. 1. The precipitation is also low during the winter period compared to that during the summer period. Fig. 3 shows the cumulative PET and cumulative precipitation used to create the atmospheric boundary condition. The graphical illustration of

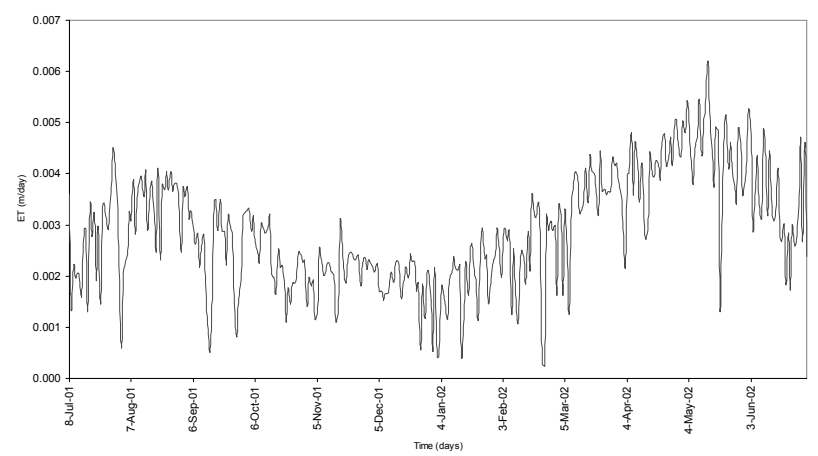

Figure 2: $\quad$ Computed potential ET (mm/day).

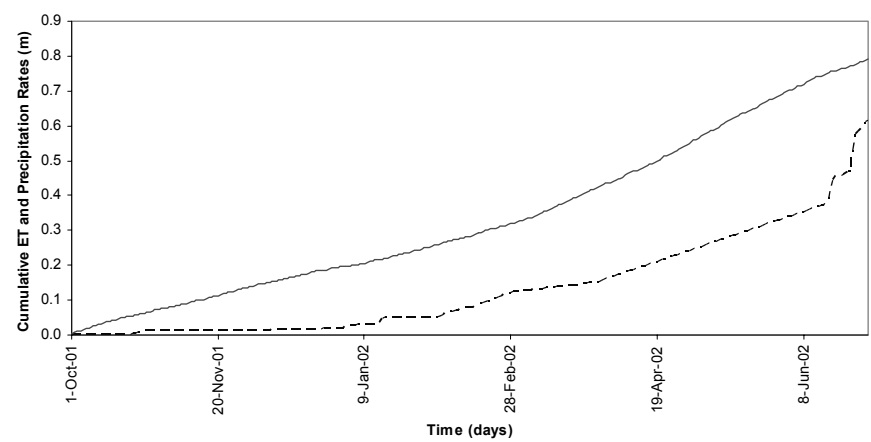

Figure 3: Variation of cumulative PET and precipitation. 


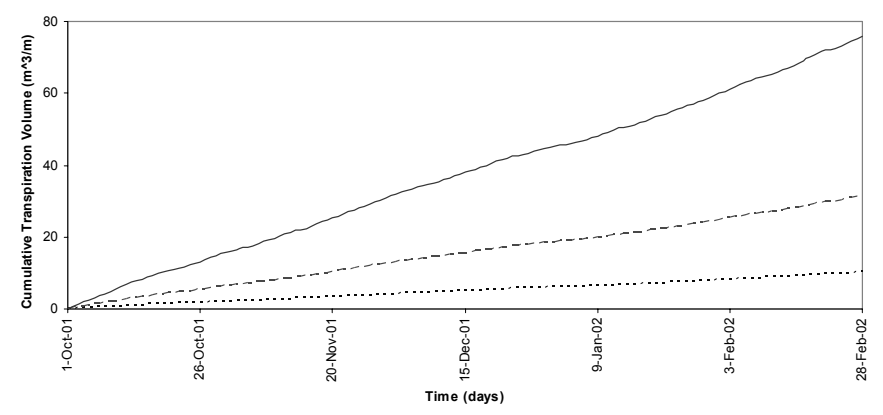

Figure 4: Change in cumulative transpiration due to urbanization.

decrease in cumulative transpiration with increase in urbanization is shown in fig. 4. Due to the presence of similar weather conditions from October to February, the variation of cumulative transpiration volume with time is more or less linear. After 150 days the cumulative transpiration is reduced by $86.4 \%$ when urbanization increases to $75 \%$.

\subsection{Impacts of increase in impervious cover on infiltration and surface run-off}

When natural landscape is not disturbed precipitation mainly turns into infiltration and evapotranspiration. The porous and natural landscapes trap rainwater and allow them to filter gradually into the ground. In contrast, impervious surfaces created by urbanization prevent rainwater from infiltrating, there-by lowering the infiltration volume and increasing the surface run-off.

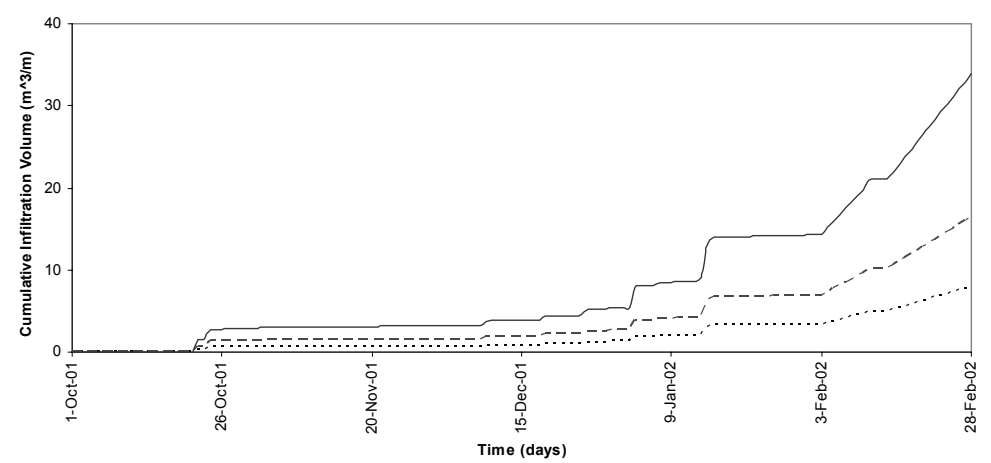

Figure 5: Change in cumulative infiltration due to urbanization.

The graphical illustration of decrease in cumulative infiltration due to increase in urbanization is shown in fig. 5. After 150 days the cumulative infiltration volume reduced by $76.4 \%$. The loss of infiltration lowers the groundwater level and stream flows during the dry weather and diminished 
ground water levels desiccate wetlands and declines wetlands biodiversity. After 150 days, the cumulative surface run-off volume increased tremendously for both $50 \%$ and $75 \%$ increase in urbanization. In the computations, it is assumed that the run-off from urbanized impervious land is directly diverted with sewer systems to the creek or to an urban storage retention pond. Without proper storage an excessive amount of run-off during a short period of time increases the possibility of flooding in the creek.

\subsection{Impacts of increase in impervious cover on base flow}

The gradual draining of stored groundwater to streams and lakes supports the low flow or base flow in streams. Impervious surfaces created by urbanization prevent rainwater from infiltrating, resulting a decline in ground water level and base flow. Spinello and Simmons [14] identified loss of ground water through sanitary sewers as the main cause for reduction in base flow. The excess storm water runoff from urbanized areas upstream is routed quickly either to a storm water storage pond or directly to an adjacent stream. Therefore, after urbanization, the flow in streams is dominated by storm flow, and base flow is small and intermittent (Stumm and $\mathrm{Ku}$ [15]). On the other hand, stream flow in the undeveloped parts of stream is dominated by base flow.

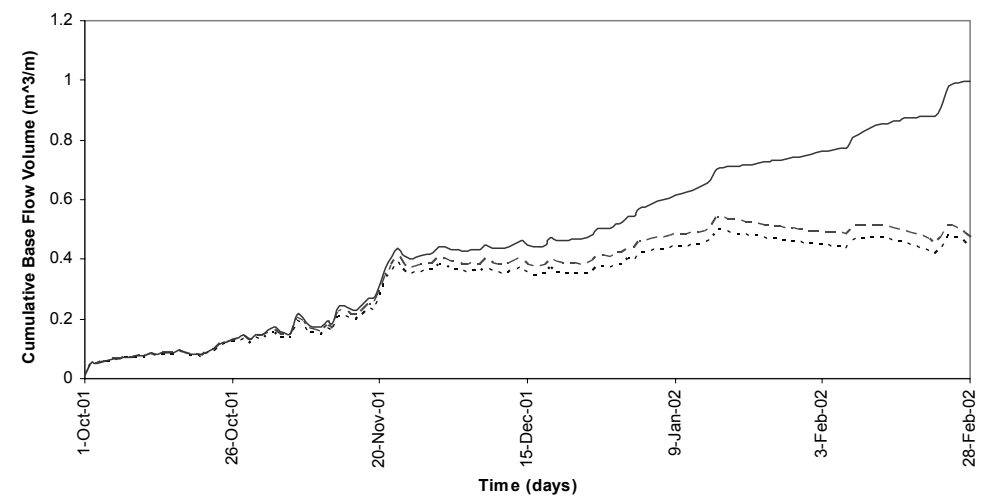

Figure 6: Change in cumulative base flow due to urbanization.

The change in cumulative base flow component due to urbanization is shown in fig. 6. As expected, highest volume of base flow corresponds with zero urbanization. With progress in time, the gap between the urbanized and nonurbanized base flow components widens. The base flow decreased by $55 \%$ after 150 days for $75 \%$ increase in urbanization.

\section{Summary and conclusion}

Land development through urbanization plays a significant role in changing the hydrologic balance in a watershed. A two-dimensional finite element variable saturation flow model is coupled with a digital terrain analysis to quantify the 
impacts of urbanization on hydrology of shallow water table environments. The ground surface is sealed to infiltration for a fraction of the surface corresponding to urbanized land. In addition an increase in impervious cover due to urbanization causes surface run-off to increase tremendously. Simulations done to assess the influences of slope on local hydrology indicated that landscapes with mild slopes have less base flow than steep slopes. Effect of surface slope on infiltration is found to be negligible due to the presence of high porosity sandy soil at this site.

\section{References}

[1] United Nations, Population Division. World Urbanization Prospects. 1994

[2] World Urbanization Prospects: The 2005 Revision, Pop. Division, Department of Economic and Social Affairs, UN

[3] Dougherty, M, et al. (2006) Quantifying Long Term NPS Pollutant Flux in an Urbanizing Watershed, ASCE Journal of Environmental Engineering, April 2006/547

[4] EPA, 2003. Protecting Water Quality from Urban Runoff, EPA 841-F-03003.

[5] Randolph, J. (2004), Environmental Land Use Planning and Management, Island Press, Washington, D.C., 664

[6] IAGLR (International Association of Great Lakes Research) 2002 Linking Science and Policy for Urban Nonpoint Source Pollution in the Great Lakes Region. Ann Arbor, Mich: IAGLR (http://www.iaglr.org /scipolicy/nps/)

[7] American Forests, 1999. www.americanforests.org.

[8] Simunek. J., Sejna, M., and van Genuchten, M.Th., 1999. The HYDRUS2D software package for simulating two-dimensional movement of water. Heat and multiple solutes in variably saturated media. Version 2.0, IGWMC-TPS-53, International Ground Water Modeling Center, Colorado School of Mines, Golden, Colorado, 251pp.

[9] Carlisle, V.W., Sodek, F., Collins, M.E., Hammond, L.C. and Harris, W.G., 1989. Characterization Data foe Selected Florida Soils, Soil Survey, Soil Conservation Service, U.S Department of Agriculture, Report No.89-1, Florida.

[10] Feddes, R. A., Kiwalik, P. J. and Zaradny, H., 1978. Simulations of Field Water Use and Crop Yield, John Wiley and Sons, New York.

[11] Diodato, D.M., 2000. Review: HYDRYS-2D, Computer Spotlights, Ground Water, 38 (1): 10-11.

[12] Van Genuchten, M.Th., 1980. A Closed-form Equation for Predicting the Hydraulic Conductivity of Unsaturated Soils, Soil Science Society American Journal, 44: 892-898.

[13] De Silva, M.S., 2003. Simulating Root Water Uptake with Heterogenous Vegetation Cover, Ph.D Dissertation, University of South Florida, Tampa, Florida. 
[14] Spinello, A.G., and Simmons, D.L., 1992. Base Flow of 10 South Shore Streams, Long Island, New York, 976-85 and the effects of Urbanization on Base Flow and Flow Duration, USGS Water Resources Investigation Report 90-4205.

[15] Stumm, F. and Ku, H.F.H., 1997. Urbanization and Recharge in the Vicinity of East Meadow Brook, Nassau County, New York; Part 2Effect of urban Runoff on the Hydrology of the Headwaters of East Meadow Brook, 1989-90, USGS Water Resources Investigation Report $97-4063$. 